\title{
PROPOSTA DE UMA SEQUÊNCIA DIDÁTICA PARA O ESTUDO DOS TRANSGÊNICOS A PARTIR DA ABORDAGEM CTS
}

\author{
Jonise Marques de Oliveira, Lenicy luCAS de Miranda Cerqueira \\ Universidade Federal de Mato Grosso - UFMT \\ <jonisemarques20@gmail.com>.<lenicy.cerqueira@gmail.com> \\ DOI: $10.21439 /$ conexoes.v15i0.2129
}

\begin{abstract}
Resumo. Esta pesquisa contextualiza o tema transgenia no âmbito de uma sequência didática no ensino de Ciências em relação a pressupostos dados pela abordagem Ciência-Tecnologia-Sociedade (CTS). Nessa perspectiva, este artigo teve como objetivo avaliar uma proposta de sequência didática, centrada no tema transgênicos, apontando as contribuições do uso da abordagem CTS para o ensino de Ciências, na Educação Básica. A proposta didática foi realizada com oito professores da área de Ciências Naturais da Escola Estadual Professor Heliodoro Capistrano da Silva, Município de Cuiabá-MT. A coleta de dados desta pesquisa ocorreu por meio da aplicação de um questionário. A partir dos resultados obtidos foi possível verificar que os participantes desta pesquisa consideram que a sequência didática, com a temática transgênicos, contribui para a apropriação e a contextualização do conhecimento por meio da abordagem CTS e colabora, significativamente, para a compreensão do conhecimento científico e das suas interrelações com a sociedade e a tecnologia.
\end{abstract}

Palavras-chaves: Sequência didática. Transgênicos. Ensino de Ciências. CTS.

\section{PROPOSAL FOR A TEACHING SEQUENCE FOR THE STUDY OF TRANSGENICS FROM THE STS APPROACH}

\begin{abstract}
This research contextualizes the transgenic theme within the scope of a didactic sequence in the teaching of Sciences in relation to assumptions given by the Science-Technology-Society approach (STS). In this perspective, this article aimed to evaluate a didactic sequence proposal, centered on the transgenic theme, pointing out the contributions of the use of the STS approach to the teaching of Sciences, in Basic Education. The didactic proposal was carried out with eight teachers in the area of Natural Sciences at the Professor Heliodoro Capistrano da Silva State School, Municipality of Cuiabá-MT. The data collection for this research occurred through the application of a questionnaire. From the results obtained it was possible to verify that the participants of this research consider that the didactic sequence, with the transgenic theme, contributes to the appropriation and contextualization of knowledge through the STS approach and contributes significantly to the understanding of knowledge scientific research and its interrelationships with society and technology.
\end{abstract}

Keywords: Transgenics. STS. Didactic sequence. Science teaching.

\section{INTRODUÇÃO}

Este artigo traz um recorte da dissertação de mestrado intitulada: Proposta de uma sequência didática para o estudo dos transgênicos a partir da abordagem CTS, que teve como objetivo principal apresentar e avaliar uma proposta de sequência didática, centrada no tema transgênicos, apontando as contribuições do uso da abordagem CTS para o ensino de Ciências na Educação Básica.

É frequente se encontrar um ensino conduzido na transmissão de conteúdos de maneira fragmentada e descontextualizada. Para Freire (1996), a educação não pode ser caracterizada como depósito de conteúdo, mas que relacione o ser humano e o mundo, ou seja, a educação deve ter um caráter popular e libertador. Nesse contexto, as possibilidades de uma formação crítica, cidadã e da capacidade de compreender o seu papel na sociedade podem ser dificultadas.

Diferentemente do modelo de educação bancária, com as novas abordagens de ensino se tem a perspectiva de que o aluno seja o sujeito de sua aprendizagem para sua formação como cidadão. Nessa direção, destaca-se a abordagem CTS no ensino de Ciências, que conforme 
Cerezo (1998) tem o objetivo de preparar os alunos, enquanto cidadãos, para participar ativamente do processo democrático de tomada de decisões na sociedade, quanto às aplicações e implicações do desenvolvimento científico e tecnológico.

Segundo Acevedo et al. (2002), os estudantes precisam desenvolver a capacidade de resolver problemas e tomar decisões relativas às questões científicas, tecnológicas e sociais com as quais se deparam como cidadãos.

Dessa forma, é necessário que os professores estejam preparados para a implementação da abordagem CTS, em sua prática docente, levando em consideração que a contextualização dos conteúdos, por meio das relações entre o conhecimento científico, aspectos tecnológicos e questões sociais surgem como de fundamental importância.

A contextualização das aulas de Ciências tem sido destacada nos documentos oficiais, que definem um conjunto progressivo de aprendizagens que todos os alunos devem desenvolver ao longo da Educação Básica. Partindo dessa perspectiva, neste estudo se abordará a temática transgênicos, enquanto controvérsias sociocientíficas de potencial uso pedagógico no ensino de Ciências, buscando articular o conteúdo, que é próximo da realidade dos alunos com a abordagem CTS, priorizando assim a formação integral do aluno.

As relações CTS, muitas vezes, visam promover a alfabetização científica dos cidadãos para que os conhecimentos científicos e tecnológicos sejam democratizados, permitindo que os mesmos participem, efetivamente, da sociedade na qual fazem parte.

A abordagem CTS possui respaldo nos documentos oficiais da educação brasileira. A Lei de Diretrizes e Bases da Educação (LDB) garante que formar cidadãos críticos significa preparar para a vida e para o exercício da cidadania (BRASIL, 1996). Nesse sentido, compreende-se que os objetivos apresentados na LDB se configuram no enfoque CTS.

Pinheiro, Silveira e Bazzo (2007) destacam que, ao conceber o currículo como uma organização conceitual com preocupação em temas sociais, desenvolvendo atitudes que favoreçam o julgamento, mediante o estudo da ciência voltado aos interesses sociais e compreendendo as implicações sociais dos conhecimentos científico e tecnológico, a LDB entra em sintonia com o enfoque CTS. Os autores ainda apontam que o caráter interdisciplinar destacado na proposta da LDB configura-se no enfoque CTS, o qual enfatiza a quebra de fronteiras rígidas e excludentes entre os saberes. A busca de um ensino mais reflexivo e contextualizado está em sintonia com esse enfoque, que persegue também os objetivos de formar um cidadão crítico, capaz de interagir com a

\section{sociedade.}

A Base Nacional Comum Curricular (BNCC), através de sua definição de competência específica para o Ensino Médio, na área de Ciências da Natureza e suas Tecnologias, preconiza que o indivíduo, cientificamente alfabetizado, possa:

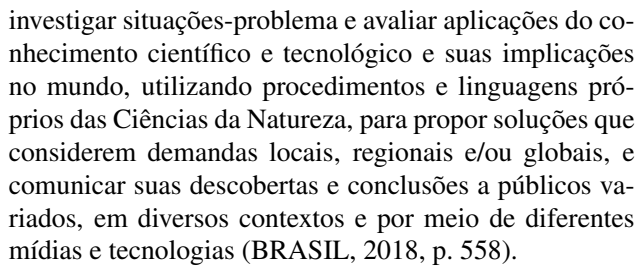

investigar situações-problema e avaliar aplicações do conhecimento científico e tecnológico e suas implicações no mundo, utilizando procedimentos e linguagens próprios das Ciências da Natureza, para propor soluções que considerem demandas locais, regionais e/ou globais, e comunicar suas descobertas e conclusões a públicos variados, em diversos contextos e por meio de diferentes mídias e tecnologias (BRASIL 2018 p. 558).

Contudo, Strieder et al. (2016), consideram que não é suficiente inserir mudanças nos documentos curriculares sem promover, de forma articulada, mudanças nas concepções e na prática pedagógica dos professores.

Diante do exposto, este estudo teve como objetivo avaliar uma proposta de sequência didática, centrada no tema transgênicos, apontando as contribuições do uso da abordagem CTS para o ensino de Ciências, na Educação Básica.

\subsection{Importância da contextualização dos transgê- nicos nas relações $\mathrm{CTS}$}

Mesmo com o desenvolvimento no campo científico e tecnológico, observa-se o despreparo dos estudantes para lidar com alguns assuntos. A transgenia é um exemplo de temática que é discutida no contexto escolar e divulgada no meio acadêmico e midiático, porém a população ainda possui conhecimento limitado em relação ao assunto.

Na ilustração da Figura 1 apresenta-se o estudo CTS como proposta pedagógica para o estudo dos transgênicos. O enfoque CTS relaciona-se com a temática transgênicos, pois trata-se de uma questão sociocientífica (QSC), há controvérsias, contextualização e interdisciplinaridade, princípios fundamentais identificados a partir da relação entre os mesmos. Os transgênicos se constituem como uma QSC pois é um tema de relevância social, que abrange aspectos políticos, econômicos, sociais, éticos e morais. É um tema controverso, pois é um tema polêmico, que divide opiniões e gera muitas dúvidas; é contextualizado, em razão de aproximar da realidade do aluno e por estar presente no dia-a-dia de grande parte da população; é um assunto interdisciplinar, uma vez que, pode ser desenvolvido de forma conjunta com outros professores para que o conhecimento se torne mais abrangente e significativo. Assim, é importante abordar o assunto para que os alunos tenham acesso ao conhecimento científico, se posicionando e 
tomando decisões frente aos problemas do dia-a-dia, trazendo significado para aquilo que é estudado, com apropriação do conhecimento científico (Figura 1).

Figura 1: Esquema da importância da abordagem CTS para o ensino dos transgênicos.

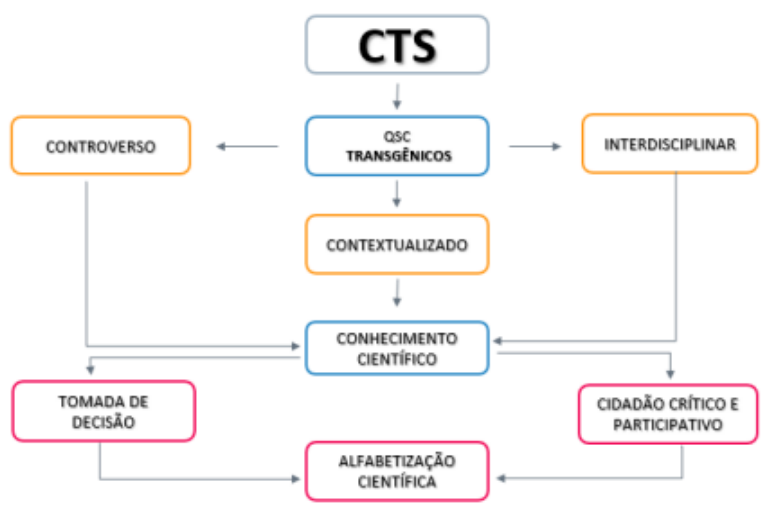

Pedrancini et al. (2008) aborda que essa realidade demonstra que nem sempre os conhecimentos adquiridos na escola possibilitam que os sujeitos ultrapassem o saber de senso comum. Dessa maneira, a escola não pode mais se limitar à transmissão de conhecimentos, mas sim promover uma educação que possibilite aos cidadãos participarem democraticamente na tomada de decisões, auxiliando-os na resolução de problemas e entendimento de situações da atualidade.

No Brasil, assim como em outras partes do Mundo, o tema transgênico é bastante controverso e vários segmentos da nossa sociedade têm se manifestado, assumindo posturas antagônicas: alguns são radicalmente contra os transgênicos, como algumas Organizações Não-Governamentais (ONGs); e em outro extremo, grandes empresas ou instituições são a favor dessa tecnologia.

Diante dos impactos causados à vida da população mundial, surgem diversas controvérsias sobre os transgênicos, pois a biotecnologia é de interesse econômico político, científico e social. Tal perspectiva se encontra no centro do movimento CTS, que se baseia fundamentalmente na crítica à neutralidade científica. Essa maneira crítica de observar a atividade científica tem influências crescentes na educação científica, aproximando-se da alfabetização científica e dos ideais educacionais de Paulo Freire - a educação dialógicaproblematizadora (AULER; DELIZOICOV, 2006).

Para Lima (2019), a abordagem Ciência, Tecnologia, Sociedade e Ambiente é importante, porque amplia alguns conhecimentos científicos, que permitem aos estudantes desconstruírem a imagem neutra da ciência, despertando o interesse por participarem de toma- das de decisões nos âmbitos científicos e tecnológicos que comprometem os indivíduos em uma perspectiva emancipatória nas questões de ordem sociais, políticas, econômicas e ambientais.

Para Ceschim e Oliveira (2018), a transgenia é uma controvérsia científica que pode ser entendida como uma QSC, pois extrapola fatores científicos e passa por uma análise de contrapontos entre riscos e benefícios.

No que se refere ao contexto da aplicação das propostas de ensino baseadas em QSC, é relevante que a aprendizagem de Ciências ocorre para a formação de cidadãos autônomos e participativos, considerando não apenas o conhecimento científico, mas também conhecimentos prévios e valores socioculturais do entorno do sujeito (HODSON, 2011).

De acordo com Takahashi, Martins e Quadros (2008), ao sugerir um trabalho envolvendo a tecnologia dos transgênicos, pensa-se na formação do cidadão crítico, capaz de inserir-se no Mundo, opinando, visualizando diferentes alternativas e optando, conscientemente, pela que for mais viável para a sua sociedade.

Diante desse quadro, a escola passa a ser definida como o lugar primordial para a partilha e construção de conhecimentos, assim como para o desenvolvimento da consciência crítica. Por isso, o assunto transgênico se faz necessário, pois a discussão sobre a temática direciona o estudante ao conhecimento científico, para que possam entender os argumentos a favor ou contra; posicionar e tomar decisões frente aos problemas do dia a dia. Assim, é de extrema importância a compreensão do assunto, já que a questão sobre os transgênicos está inserida na vida de todos.

Pedrancini et al. (2007) destacam que:

\begin{abstract}
Torna-se urgente a necessidade de uma prática pedagógica que, ao invés de estimular a simples reprodução de conhecimentos, contribua para a formação de indivíduos com consciência crítica, capazes de utilizar os conhecimentos apreendidos na formação do pensamento e mobilizá-los nas diversas situações de sua vida cotidiana (PEDRANCINI et al. 2007. p. 307).
\end{abstract}

Fonseca e Bobrowski (2015) afirmam que a abordagem da Biotecnologia com seus desdobramentos sociais é importante para a prática do pensamento crítico dos estudantes. No entanto, para que isso ocorra, Takahashi, Martins e Quadros (2008) apontam que o professor ao trabalhar um tema controverso, em sala de aula, precisa ter estratégias diferenciadas de ensino.

Pedrancini et al. (2007) ressaltam ainda a necessidade da apropriação dos conceitos científicos, que estão na base dos atuais avanços biotecnológicos, para que os sujeitos possam compreender e se posicionar de modo crítico e democrático acerca de seus benefícios, riscos 
e implicações. Conforme Bachelard (1996), a apropriação do conhecimento científico não ocorre pela continuidade dos saberes do senso comum, ou seja, a aprendizagem de novos conteúdos requer mudanças conceituais similares àquelas ocorridas nas revoluções científicas.

Com relação à prática de controvérsias controlada em sala de aula, Chrispino (2013) demonstrou que essa estratégia é eficaz para promover o debate de temas que suscitam visões, valores e crenças diferenciadas. Ainda, sobre a prática de controvérsia controlada, Vidal e Chrispino (2016) afirmam que:

\begin{abstract}
esta técnica traz muitos benefícios à discussão de temas sociocientíficos porque permite discutir de maneira dinâmica uma grande variedade de assuntos CTS, privilegiando o protagonismo dos estudantes. Também é importante ressaltar que a controvérsia controlada exige dos estudantes uma infinidade de outras competências e habilidades que só atividades como esta poderiam trabalhar: falar em público, ouvir sem intervir de maneira inadequada, levar em conta opiniões referentes a outros pontos de vista, argumentar e tentar chegar à resolução de impasses, entre outras (VIDAL; CHRISPINO 2016 p. 46).
\end{abstract}

Diante da complexidade do atual momento histórico, em que o desenvolvimento científico e tecnológico está cada vez mais presente na sociedade, as pesquisas indicam a necessidade de estimular propostas de ensino preocupadas com a real essência do papel da escola para promover uma educação, que possibilite a construção de conhecimentos, inserindo práticas pedagógicas inovadoras e temáticas atuais e polêmicas, a fim de discutir e contextualizar as informações veiculadas na mídia.

\section{ASPECTOS METODOLÓGICOS}

A presente pesquisa é de natureza qualitativa, do tipo descritiva. Esta modalidade de pesquisa tem como princípio esclarecer questões e propiciar reflexões que podem modificar ideias e conceitos existentes sobre determinada temática. O principal instrumento é o pesquisador e a fonte de dados é o ambiente, em que os fatos de seu interesse se encontram ao discutir as características da pesquisa qualitativa. Creswell (2007, p. 186) destaca que o interesse do pesquisador ao estudar um determinado problema é verificar como o problema se manifesta nas atividades, nos procedimentos e nas interações cotidianas.

Conforme Gil (2008, p. 28), a pesquisa descritiva tem como objetivo descrever, criteriosamente, os fatos e os fenômenos de determinada realidade. A grande contribuição das pesquisas descritivas é proporcionar novas visões sobre uma realidade já conhecida.

A pesquisa foi realizada na Escola Estadual Professor Heliodoro Capistrano da Silva, Município de Cui- abá - MT. A escola oferta a Educação básica, Ensino Fundamental e Médio, na modalidade de Educação de Jovens e Adultos (EJA). O estudo teve como públicoalvo oito professores do Ensino Médio, todos da área das CN, sendo quatro de Biologia, dois de Química e dois de Física. Quanto à formação acadêmica, um professor possui doutorado, três professores possuem o título de mestre, três docentes possuem especialização e um graduação.

Para que os professores pudessem participar da pesquisa, foi solicitada a autorização dos mesmos, por meio do Termo de Consentimento Livre e Esclarecido, no qual foram informados os objetivos do estudo, suas implicações e seus direitos como participantes. A pesquisa foi submetida e aprovada pelo Comitê de Ética e Pesquisa (CEP) da Universidade Federal de Mato Grosso (UFMT).

Deste modo, para que pudessem participar da pesquisa, foi solicitada a autorização dos participantes, por meio do Termo de Consentimento Livre e Esclarecido, no qual foram informados sobre o objetivo do estudo, suas implicações e seus direitos como participantes.

A coleta de dados desta pesquisa ocorreu por meio da aplicação de um questionário. O questionário foi disponibilizado na plataforma Google Forms. Por meio de um link, via aplicativo de mensagens instantâneas (Whatsapp), os participantes foram direcionados diretamente para o questionário, que continha 20 questões, contendo três partes: a primeira parte do questionário refere-se aos dados pessoais, acadêmicos e profissionais dos participantes da pesquisa; na segunda parte buscouse identificar as ações didático-pedagógicas e as concepções dos professores sobre CTS; e, após a apresentação da SD, os professores puderam avaliá-la por meio das questões presentes na terceira parte do questionário.

A seguir apresenta-se algumas questões presentes no questionário: Você tem conhecimento a respeito do ensino de Ciências baseado na perspectiva CTS? Você acha importante relacionarmos o desenvolvimento da ciência e da tecnologia com o dia-a-dia dos nossos alunos? Para a temática Transgênicos você achou relevante a sequência didática proposta? De acordo com as atividades desenvolvidas na sequência didática, qual é o grau de importância no processo de ensino e aprendizagem? Quais as habilidades que podem ser adquiridas pelos alunos após a aplicação da sequência didática?

Marconi e Lakatos (2003) definem o questionário como um instrumento de coleta de dados, constituído por uma série ordenada de perguntas, de acordo com um critério predeterminado e que tem por objetivo coletar dados de um grupo de respondentes. 
Foi proposto como objeto de investigação, a avaliação de uma sequência didática, que será apresentada a seguir, como possibilidade de auxiliar os professores da Educação Básica, de modo a colaborar com suas aulas e, consequentemente, a aprendizagem dos estudantes, pois o ato de se planejar atividades, de forma sequencial, auxilia o professor a ter uma visão complexa da ciência que ensina, se distanciando de um ensino fragmentado, mas para isso é imperioso ter conhecimento teórico do conteúdo e de diversas maneiras didáticas para o planejamento de todas as atividades (ZABALA 1998).

Dessa forma, apresenta-se a SD, pretendendo contribuir com a prática pedagógica dos professores da área de Ciências Naturais. Foram planejadas seis atividades pedagógicas descritas a seguir com seus respectivos desenvolvimentos (Tabela 1).

\section{RESULTADOS E DISCUSSÃO}

Para os participantes da pesquisa, a sequência didática proposta pode contribuir com o processo de ensino e aprendizagem sobre a temática transgênicos; sendo que $87,5 \%$ acreditam que a sequência didática pode incentivar a construção do conhecimento dos estudantes e $12,5 \%$ disseram que pode contribuir parcialmente.

A Figura 2 mostra a importância das atividades pelos professores, com relação a sequência didática no processo de aprendizagem. De acordo com o grau de importância, foi estabelecido de 1 a 5, sendo que 1 foi considerado como menos importante e 5 mais importante.

Figura 2: Importância das atividades no processo de aprendizagem dos alunos

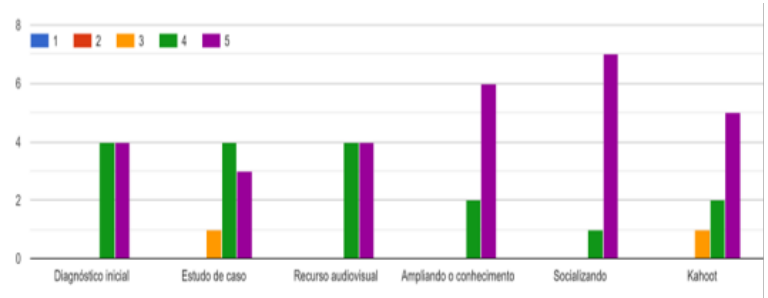

A atividade considerada mais importante para os professores investigados foi a atividade "Socializando"; em seguida, a atividade "ampliando o conhecimento", depois "Kahoot" como recurso na verificação da aprendizagem.

A primeira atividade, "Diagnóstico inicial", tem como objetivo esclarecer os conhecimentos prévios dos alunos sobre os transgênicos e compreender a diferença dos alimentos transgênicos, orgânicos e conven- cionais. É importante verificar o conhecimento prévio dos alunos sobre o assunto para que conheça o nível de habilidades apresentadas pelos estudantes. Conforme (BRÃO; PEREIRA 2015), quando o professor reproduz os conteúdos e os estudantes acriticamente o assimilam, não se apresenta nenhum diferencial em relação às concepções prévias dos estudantes.

O objetivo da segunda atividade, "Estudo de Caso", foi de desenvolver a habilidade na resolução de problemas e identificar os argumentos utilizados pelos estudantes sobre as controvérsias apresentados nos casos. A atividade contribuiu-se para a formação de um pensamento crítico-reflexivo e na tomada de decisão consciente sobre a Ciência \& Tecnologia, pois a partir de um tema controverso as discussões entre os alunos podem ser mais amplas.

$\mathrm{Na}$ terceira atividade, "Recurso audiovisual", o objetivo foi de apresentar a produção dos transgênicos, apontar a importância da biotecnologia para a sociedade e analisar as vantagens e desvantagens dos transgênicos, por meio de vídeos. A utilização de vídeos nas aulas, de maneira adequada e integrada aos conceitos, estimula a sensibilidade para analisar, criticar, refletir e contribuem também para otimização do tempo para o planejamento das práticas docentes. Conforme Moran (1995, p. 29): "a linguagem audiovisual desenvolve múltiplas atitudes perceptivas: solicita constantemente a imaginação e reinveste a afetividade com um papel de mediação primordial no mundo". É fundamental que os professores planejem suas aulas dentro dos objetivos didático-pedagógicos. O uso de vídeo em sala de aula é um instrumento que pode auxiliar a ação pedagógica, ajudando a relacionar os fatos com o mundo real. Para o autor o vídeo nos seduz, informa, projeta em outras realidades (imaginário) em outros tempos e espaços.

O objetivo da quarta atividade, "Ampliando o conhecimento", foi de ampliar o conhecimento acerca dos transgênicos, através de ferramentas didáticopedagógicas complementares, que auxiliam o professor no processo de ensino e aprendizagem. É preciso que o professor saiba utilizar a internet como instrumento pedagógico. Conforme Nascimento e Vasconcelos (2017), as interfaces representam para os professores uma nova estratégia de ensino e que seu uso dinamiza as aulas, despertando nos alunos a criatividade, a imaginação e possui, às vezes, uma linguagem de fácil entendimento.

Na quinta atividade, "Socializando", o objetivo foi de estimular a capacidade de reflexão e de construção de argumentação embasada sobre os transgênicos. Cria-se oportunidades para que os alunos desenvolvam habilidades argumentativas, em sala de aula, de forma crítica, 


\section{ATIVIDADE}

Atividade 1 - Diagnóstico Inicial

Atividade 2 - Estudo de Caso

Atividade 3 - Recurso audiovisual

Atividade 4 - Ampliando o conhecimento

Atividade 5 - Socializando

Atividade 6 - Bio Game Quiz

\section{DESENVOLVIMENTO}

Os alunos realizam uma pesquisa, observando os alimentos que mais consomem, classificando-os em transgênicos, orgânicos e convencionais, identificando nas embalagens dos alimentos transgênicos os selos de certificação. Depois, o professor propõe uma discussão entre os estudantes, na qual os mesmos irão expor suas dúvidas, conhecimentos e argumentos sobre a atividade realizada.

Uma dada situação problema é colocada e o estudante deverá construir e pensar alternativas para resolver a questão problema. A sala de aula é dividida em grupos. O professor distribui dois casos por grupo para a leitura e discussão. Dois representantes de cada grupo são escolhidos para apresentar suas argumentações em sala.

O professor apresenta aos estudantes vídeos que apresentam diferentes reflexões sobre o tema transgênicos. Após a exibição dos vídeos, o professor realiza uma pergunta problematizadora e retoma os pontos mais importantes abordados nos vídeos, favorecendo assim um momento de discussão, para que os alunos possam expressar suas ideias e opiniões.

O professor orienta os alunos, de forma individual ou em grupo, com vistas a ampliação do conhecimento sobre os transgênicos, por meio das Tecnologia de Informação e Comunicação (TIC'S). A sala de aula é dividida em dois grupos. Cada grupo organiza um discurso e uma estratégia para o debate. A metade da sala argumenta acerca dos riscos do emprego da biotecnologia dos transgênicos e a outra metade defende, argumentando suas vantagens. Os alunos apresentam suas dúvidas, questionamentos e argumentos, permitindo-se o confronto de ideias em torno dos transgênicos. O professor media a argumentação apresentada pelos alunos e levanta alguns questionamentos.

Utilizou-se a plataforma Kahoot, para desenvolver-se o "BIO GAME QUIZ". As perguntas e alternativas são projetadas e as alternativas são associadas a uma cor e figura geométrica. Os alunos em seus celulares, visualizam apenas as cores e as figuras e selecionam a figura/cor que corresponde a alternativa correta. A pontuação ocorre em função do tempo e da resposta correta, e o aluno recebe em seu dispositivo um retorno de erro ou de acerto. É possível observar a resposta correta e o número de alunos que acertaram esta questão, bem como as demais alternativas marcadas. No término das questões, é possível verificar na tela do professor a classificação, mostrando as pontuações mais altas. podendo promover o engajamento dos mesmos em debates sobre temas relacionados à Ciência e sobre seus impactos e influências no contexto social. Conforme Silva e Silva (2016), trata-se não somente de criar essas oportunidades, mas de sequenciar atividades de ensino, que propiciem aos alunos, habilidades que os permitam investigar, participar, argumentar suas opiniões ativamente em discussões científicas. 
O objetivo da sexta atividade, "Bio Game Quiz", foi de avaliar o conhecimento adquirido pelos alunos sobre os transgênicos e desenvolver a motivação e interesse dos alunos para participarem ativamente das aulas. Permite que o professor atue como mediador do processo de ensino e aprendizagem e os estudantes ativos na construção de novos saberes. Para Sande e Sande (2018), as tecnologias lúdicas incorporadas aos métodos tradicionais de ensino possibilitam a motivação dos estudantes e maximizam a interação entre estudantes e professores.

Todos os professores investigados acreditam que os objetivos propostos por cada atividade da sequência didática podem ser alcançados.

Os resultados mostraram que $87,5 \%$ dos professores acreditam que a sequência didática elaborada possibilita que o estudante aplique conhecimentos nas situações do seu cotidiano, tomando decisões e atuando de forma consciente. O conhecimento científico deve ser articulado com o cotidiano dos alunos, envolvendo e estimulando o aprendizado dos alunos. Conforme Alves (2018), para que o professor consiga transpor o conhecimento científico é imprescindível o uso de metodologias que levem o aluno a pensar, a questionar, a debater, a pesquisar e a interagir com seus colegas, a ponto de tomar uma decisão e obter uma postura diante de um assunto ou tema tratado em sala de aula.

Baseados nos dados levantados, por meio do questionário, os participantes da pesquisa expressaram suas opiniões relacionadas às habilidades que poderão ser adquiridas pelos alunos, após a aplicação da SD, conforme apresentado na Figura 3 .

Figura 3: Habilidades adquiridas pelos alunos após a aplicação da sequência didática

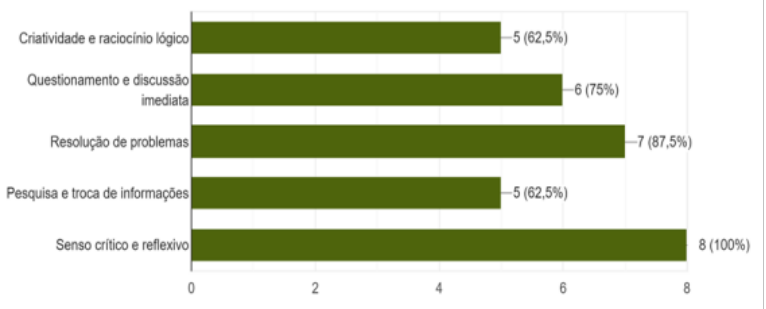

Conforme a Figura 3 , todos os participantes da pesquisa $(100 \%)$ consideraram o senso crítico e reflexivo como a habilidade mais importante que pode ser adquirida pelo aluno, após a aplicação da sequência didática; seguida da habilidade resolução de problemas $(87,5 \%)$, depois pelo questionamento e discussão $(75 \%)$.

É importante ressaltar que, um indivíduo que apresenta um senso crítico e reflexivo, contribui significa- mente para a transformação dos fatos e da realidade, visto que, ao adquirir o conhecimento, terá capacidade de tomar decisões e resolver problemas. Nesse sentido, o professor deve reconhecer seu papel frente à formação crítica do aluno, pois o conhecimento estático e descontextualizado, torna-se o aluno um mero expectador do processo de ensino aprendizagem.

O questionamento desempenha um papel importante no processo de aprendizagem, possibilitando que o aluno analise, reflita e discuta sobre determinada situação. Dessa forma, o estudante desenvolve um pensamento crítico, contribuindo positivamente com a construção da autonomia, incentivando-o a formar suas próprias opiniões e decisões.

A contextualização do tema transgênicos no ensino de Ciências, pode contribuir por meio de argumentos a importância de o aluno observar, pensar e refletir no seu dia-a-dia. Por meio da problematização os alunos sentem-se motivados, sanando suas dúvidas, chegando aos resultados. A partir da temática do estudo, os questionamentos apresentados aos alunos, podem contribuir com o processo de ensino e aprendizagem, levando-os a pensar e contrapor suas ideias, possibilitando assim, o desenvolvimento de posicionamentos fundamentais ao exercício da cidadania e a construção de novos conceitos relacionados ao tema abordado.

\section{CONSIDERAÇÕES FINAIS}

Ficou evidente a pouca familiaridade dos docentes investigados com a abordagem CTS no ensino e a realização de aulas baseadas na contextualização com enfoque CTS. Porém, após a apresentação e estudo da abordagem CTS no ensino, a maioria dos professores compreenderam a importância de debater temas relacionados à CTS no ensino de Ciências.

A introdução da abordagem CTS além de contribuir para a aprendizagem no ensino de Ciências, desenvolve também o conhecimento científico, tão necessário para que os estudantes participem das decisões referentes aos problemas das mais variadas situações que o cercam diariamente. Por meio da abordagem CTS é possível que ocorra mudança de atitudes e formação de opiniões de alguns dos alunos, com argumentos mais consistentes e conscientes dos seus deveres como cidadãos.

Mesmo apresentando visões superficiais e generalistas sobre o ensino CTS, a maior parte dos participantes da pesquisa considera que a abordagem CTS contribui para a construção do conhecimento científico e para a formação de cidadãos críticos.

A sequência didática desenvolvida, propõe atividades que atendem as características de um material com 
PROPOSTA DE UMA SEQUÊNCIA DIDÁTICA PARA O ESTUDO DOS TRANSGÊNICOS A PARTIR DA ABORDAGEM CTS

abordagem CTS, com a finalidade de fornecer ao estudante ferramentas para uma reflexão intensa acerca da realidade, uma vez que as temáticas são problematizadas no cotidiano de cada aluno. Assim, o aluno é direcionado à discussão e à busca de resoluções ou alternativas que o auxiliem nas tomadas de decisões com base no conhecimento científico e senso crítico.

Verificou-se que os participantes desta pesquisa consideram que a sequência didática, com a temática transgênicos, contribui para a apropriação e a contextualização do conhecimento por meio da abordagem CTS e colabora, significativamente, para a compreensão do conhecimento científico e das suas inter-relações com a sociedade e a tecnologia.

A temática abordada pode ser desenvolvida, de forma conjunta, com outros professores, assim o conhecimento passa a ser mais abrangente e significativo, formando alunos mais conscientes e reflexivos na busca da compreensão da realidade que o cerca.

De acordo com Martínez, Lozano et al. (2013), a partir do enfoque CTS, o professor não se limita ao domínio de conhecimentos disciplinares, o que requer uma compreensão ampla dos aspectos filosóficos, éticos, morais e políticos da Ciência e Tecnologia. A abordagem CTS em sala de aula, demanda abertura para a discussão de aspectos controversos e condições para análise das contribuições e limites das atividades científicas e tecnológicas na sociedade.

Outras considerações, trazidas por Gomes (2015), envolvem o aspecto de que o professor que reflete criticamente sobre sua própria prática possibilita o desenvolvimento da abordagem CTS no ensino de Ciências. É preciso haver mudanças na maneira de pensar a educação e de planejar as aulas, colaborando assim com desenvolvimento de aprendizagens mais significativas para os estudantes.

O protagonismo dos jovens é uma condição relevante na sociedade da informação, para que a instituição escolar possa assumir seu papel como espaço de construção democrática e promoção de conhecimentos para estes mesmos jovens. A utilização de estratégias pedagógicas diversificadas permite uma participação mais efetiva dos estudantes, propiciando o desenvolvimento de outras habilidades, como a capacidade de argumentação, a reflexão crítica e a criatividade.

\section{REFERÊNCIAS}

ACEVEDO, J. A.; ALONSO, Á. V.; MAS, M.; ROMERO, P. Persistencia de las actitudes y creencias cts en la profesión docente. Revista electrónica de enseñanza de las Ciencias, v. 1, n. 1, p. 1-27, 2002.
ALVES, F. F. d. S. O impacto da perspectiva Ciência, Tecnologia e Sociedade (CTS) na disciplina de Biologia no ensino médio tecnológico. Dissertação (Mestrado em Ensino de Ciências e Matemática) Universidade Federal do Amazonas, Manaus, 2018.

AULER, D.; DELIZOICOV, D. Ciência-tecnologiasociedade: relações estabelecidas por professores de ciências. Revista electrónica de enseñanza de las ciencias, v. 5, n. 2, p. 337-355, 2006.

BACHELARD, G. A formação do espírito científico. 1. ed. Rio de Janeiro: Contraponto, 1996.

BRÃO, A. F. S.; PEREIRA, A. M. T. B. Biotecnétika: Possibilidades do jogo no ensino de genética. Revista Electrónica de Enseñanza e las Ciencias, v. 14, n. 1, p. 55-76, 2015.

BRASIL. Lei de Diretrizes e Bases da Educação

Nacional. Brasilia, 1996. Disponível em: <http://www.planalto.gov.br/ccivil_03/Leis/L9394> Acesso em: 11 jun. 2020.

Base Nacional Comum Curricular.

Brasília: MEC, 2018. Versão entregue ao

CNE em 03 de abril de 2018. Disponível em:

$<$ http://basenacionalcomum.mec.gov.br/abase/>

Acesso em: 11 mai. 2020.

CEREZO, J. A. L. Ciencia, tecnología y sociedad: el estado de la cuestión en europa y estados unidos. Revista iberoamericana de educación, Organización de Estados Iberoamericanos para la Educación, la Ciencia y la ..., v. 1, n. 18, p. 41-68, 1998.

CESCHIM, B.; OLIVEIRA, T. B. Transgênicos, letramento científico e cidadania. Revista brasileira Ensino Ciências Tecnologia, v. 11, n. 1, p. 131-154, 2018.

CHRISPINO, A. O uso do enfoque cts e controvérsias tecnocientíficas por professores do ensino médio: Um exemplo da capacitação em serviço em grande escala. Enseñanza de las ciencias: revista de investigación y experiencias didácticas, Extra, n. Extra, p. 914-918, 2013.

CRESWELL, J. W. Projeto de Pesquisa: Métodos qualitativo, quantitativo e misto. 2. ed. Porto Alegre: Artmed, 2007.

FONSECA, V. B.; BOBROWSKI, V. L. Biotecnologia na escola: a inserção do tema nos livros didáticos de biologia. Acta Scientiae, v. 17, n. 2, p. 496-509, 2015. 
PROPOSTA DE UMA SEQUÊNCIA DIDÁTICA PARA O ESTUDO DOS TRANSGÊNICOS A PARTIR DA ABORDAGEM CTS

FREIRE, P. Pedagogia da autonomia: Saberes necessários à prática educativa. 25 . ed. São Paulo: Paz e Terra, 1996.

GIL, A. C. Métodos e técnicas de pesquisa social. 5. ed. São Paulo: Atlas, 2008.

GOMES, L. S. Práticas pedagógicas de professores formadores e abordagem CTS: o ensino de Ciências rumo a novas percepções neste século XXI.

Dissertação (Mestrado em Educação em Ciências e Matemática) - Universidade Federal do Pará, Belém, 2015.

HODSON, D. Looking to the Future: Building a Curriculum for Social Activism. Auckland: Sense, 2011.

LIMA, L. A. d. A compreensão de estudantes de diferentes níveis de ensino sobre transgênicos. Dissertação (Mestrado em Educação) - Universidade Federal da Bahia, Salvador, 2019.

MARCONI, M. d. A.; LAKATOS, E. M. Fundamentos de Metodologia Científica. 5. ed. São Paulo: Atlas, 2003.

MARTÍNEZ, L. F. P.; LOZANO, D. L. P. et al. La emergencia de las cuestiones sociocientíficas en el enfoque ctsa. Góndola, Enseñanza Y Aprendizaje De Las Ciencias (Bogotá, Colombia), v. 8, n. 1, p. 23-35, 2013.

MORAN, J. M. O vídeo na sala de aula. Comunicação \& Educação, v. 2, n. 1, p. 27-35, 1995.

NASCIMENTO, E. d. S.; VASCONCELOS, C. A. d. A utilização da internet nas aulas de biologia. In: IV Encontro Alagoano de Ensino de Ciências e Matemática. 4. ed. Maceió: Programa de Pós-Graduação em Ensino de Ciências e Matemática da Universidade ..., 2017.

PEDRANCINI, V. D.; CORAZZA-NUNES, M. J.; GALUCH, M. T. B.; MOREIRA, A.; RIBEIRO, A. C. Ensino e aprendizagem de biologia no ensino médio e a apropriação do saber científico e biotecnológico. Revista Electrónica de Enseñanza de las ciencias, v. 6, n. 2, p. 299-309, 2007.

PEDRANCINI, V. D.; CORAZZA-NUNES, M. J.; GALUCH, M. T. B.; MOREIRA, A. L. O. R.;

NUNES, W. M. d. C. Saber científico e conhecimento espontâneo: opiniões de alunos do ensino médio sobre transgênicos. Ciência \& Educação (Bauru), SciELO Brasil, v. 14, n. 1, p. 135-146, 2008.
PINHEIRO, N. A. M.; SILVEIRA, R. M. C. F.;

BAZZO, W. A. Ciência, tecnologia e sociedade: a relevância do enfoque cts para o contexto do ensino médio. Ciência \& Educação (Bauru), SciELO Brasil, v. 13, n. 1 , p. 71-84, 2007.

SANDE, D.; SANDE, D. Uso do kahoot como ferramenta de avaliação e ensino-aprendizagem no ensino de microbiologia industrial. Holos, v. 1, n. 1, p. 170-179, 2018.

SILVA, M. L. M.; SILVA, M. G. L. Argumentação no ensino de biologia: uma experiência no ensino médio. ACTIO: Docência em Ciências, v. 1, n. 1, p. 70-86, 2016.

SPOLIDORO, M. M. F. Contribuição de uma controvérsia sobre transgenia para a formação crítica de alunos do ensino médio. 101 p. Dissertação (Mestrado em Ciência, Tecnologia e Educação) Centro Federal de Educação Tecnológica do Rio de Janeiro, Rio de Janeiro, 2018.

STRIEDER, R. B.; ALMEIDA, K. M.; SOBRINHO, M. F.; SANTOS, W. L. P. dos et al. A educação cts possui respaldo em documentos oficiais brasileiros? ACTIO: Docência em Ciências, v. 1, n. 1, p. 87-107, 2016.

TAKAHASHI, J. A.; MARTINS, P. F. F.; QUADROS, A. L. Questões tecnológicas permeando o ensino de química: o caso dos transgênicos. Química nova na escola, v. 29, n. 1, p. 3-7, 2008.

VIDAL, C. S.; CHRISPINO, A. A controvérsia cts da guerra a partir de uma história em quadrinhos. In: Atas da XI Jornadas Latino-americanas de Estudos Sociais da Ciência e da Tecnologia. Curitiba, PR, Brasil: ESOCITE, 2016. p. 1-12.

ZABALA, A. A prática educativa: como ensinar. 1. ed. Porto Alegre: Artmed, 1998. 